\title{
CORRECTION
}

\section{Correction to: Sequence analysis of double-strand RNA6 and RNA9 from the fungus Sclerotium hydrophilum}

\author{
Juan $\mathrm{Wu}^{1} \cdot$ Chunlan Wang ${ }^{2,3} \cdot$ Xiwu Zhu ${ }^{1,2} \cdot$ Jishuang Chen ${ }^{4}$
}

Published online: 16 November 2021

(C) Springer-Verlag GmbH Austria, part of Springer Nature 2021

\section{Correction to: Arch Virol (2017) 162:2913-2917 https://doi.org/10.1007/s00705-017-3430-1}

Because Sclerotium hydrophilum virus 1 (Accession number: KU886558 and KU886559) in Genebank was not approved and named as a species of virus by reviewer in paper in Virus Genes (https://doi.org/10.1007/s11262-016-1375-1), Sclerotium hydrophilum virus 2 in Genebank (Accession number: KX760093 and KX760094) was approved as a species of virus by reviewer in the paper named "Sequence analysis of double-strand RNA6 and RNA9 from the fungus Sclerotium hydrophilum" in Archives of Virology, and misunderstood by us and tentatively named the putative virus "Sclerotium hydrophilum virus 1". At present, the virus name in the paper in Archives of Virology is not consistent with the virus name in Genebank. But the virus name cannot be corrected in Genebank.

The original article can be found online at https://doi.org/10.1007/ s00705-017-3430-1.

Xiwu Zhu

zhuxw9999@aliyun.com

Juan $\mathrm{Wu}$

wujuan20022499@126.com

Chunlan Wang

wc16594@163.com

Jishuang Chen

biochenjs@163.com

1 Institute of Agriculture and Biotechnology, Hunan

University of Humanities, Science and Technology,

Loudi 41700, China

2 Institute of Bioengineering, Zhejiang Sci-Tech University, Hangzhou 310018, China

3 LC-BIO Technologies CO., LTD., Hangzhou 310018, China

4 Institute of Bioresource Engineering, Nanjing University of Technology, Nanjing 210009, China
Hence, the virus name "Sclerotium hydrophilum virus 1" is corrected as "Sclerotium hydrophilum virus 2"

Publisher's Note Springer Nature remains neutral with regard to jurisdictional claims in published maps and institutional affiliations. 